\title{
Successful research capacity building in academic nursing and midwifery in Ireland: An exemplar
}

\author{
Cecily Begley *, Mary McCarron, Sylvia Huntley-Moore, Sarah Condell, Agnes Higgins \\ School of Nursing and Midwifery, Trinity College Dublin, Ireland
}

\section{A R T I C L E I N F O}

\section{Article history:}

Accepted 10 September 2013

Available online $\mathrm{xxxx}$

\section{Keywords:}

Academic midwifery

Academic nursing

Research capacity building

Research development

Research excellence

Research leadership

Research metrics

Research outputs

\section{S U M M A R Y}

Background: Nursing and midwifery education have comparatively recently moved into academia in Ireland. In 2002, nurse tutors who were qualified to Master's degree level assimilated into the third-level sector. Only 11 of the 35 staff (31\%) in one university School held, or were undertaking, a PhD. In 2006, children's nursing and midwifery tutors also moved into third-level institutions. The culture of all assimilating tutors was focussed on teaching, rather than research.

Objectives: The School set ambitious plans to develop the research abilities of all academics, setting the goal that $75 \%$ of academic staff would either hold, or be undertaking, a PhD by 2010. Objectives were also set to increase external research funding, peer-reviewed publications and conference presentations.

Methods: A combination of sabbatical leaves, student stipends and periods of reduced teaching load was introduced to provide staff with protected time for doctoral studies. Funding for conference and research expenses was provided, based on the previous year's research output of publications, conference presentations and external funding submissions.

Results: By October 2010, 79\% of the 66 School staff either had ( $\mathrm{n}=23$ ), or were conducting $(\mathrm{n}=29)$, PhDs, surpassing goals set. Peer-reviewed publications and conference presentations had increased by $>20 \%$ per year and external research funding totalled $€ 6,351,101$ for the previous 5 years.

Conclusions: Strong research leadership, generous support and liberal encouragement can change a predominantly teaching-focussed culture to one of academic research excellence. This increase in research expertise will lead to better patient/client care and improved education of nursing and midwifery students.

(C) 2013 Elsevier Ltd. All rights reserved.

\section{Introduction}

Nursing and Midwifery's Move Into the Irish Academy

Research capacity building ( $\mathrm{RCB})$ is of international concern to professions such as teaching (Murray et al., 2009) and allied health professionals (White, 2003; Lazzarini et al., 2013), especially in circumstances of recent moves to university education (Boyd et al., 2009). Given that the World Health Organisation (2009) has recommended the graduate nurse, research capacity building will also remain a focus for the nursing and midwifery professions globally.

In Ireland nursing and midwifery education are comparative academic newcomers. Until 1994, all nursing and midwifery education were run on the apprenticeship model, where students undertook a certificate course of three years' duration and were employed, and paid, by the health service. From 1994/95 to 1997/8, new Schools of Nursing (or Nursing and Midwifery) were opened in third-level

\footnotetext{
* Corresponding author at: School of Nursing and Midwifery, Trinity College Dublin, 24 D'Olier St, Dublin 2, Ireland. Tel.:+353 1 8962693; fax: + 35318963001.

E-mail address: cbegley@tcd.ie (C. Begley).
}

institutes in Ireland to run the 3-year Diploma in Nursing in partnership with health-service providers. As the nursing curriculum was still taught by nurse teachers in hospital nursing schools, only a few staff were employed in third-level to teach science/social science subjects, and research, ethics, law and management. As a result of the Report of the Commission on Nursing (Government of Ireland, 1998), nursing education moved to degree level in 2002. With national union agreement, a concomitant assimilation into the third-level institutions of all nurse teachers educated to Master's level was to occur.

In a 2001 NET editorial, concern was expressed by two United Kingdom nurse academics as to the level of success or otherwise that would attend this planned national assimilation in Ireland (McKenna and Coates, 2001). The authors asserted, rightly, that these teachers would change from being experts in a mainly teaching environment to being novices in research terms in their new institutions. They believed that nurse teachers would "be expected to engage in the academic game for which they had no previous training and which was not a component of their previous job specification", and referred to them as "an endangered species" (McKenna and Coates, 2001, p. 422). The published rebuttal that followed, written by a Director of one of the new university Schools of Nursing and Midwifery in Ireland, stated that Irish nurse teachers would be "supported, encouraged and facilitated 
to develop and enhance their teaching, clinical and research profiles" (Begley, 2001, p. 596).

In 2002, the 4-year BSc in Nursing commenced across the country, followed in 2006, by the 4-year BSc Midwifery and 4.5 year BSc in Children's and General Nursing with similar assimilation of children's nursing and midwifery tutors. The culture of all tutors who assimilated was focussed on teaching and there had been no expectation in their previous posts that they should conduct research.

\section{Background on Research Capacity Building}

The nursing and midwifery literature describes various initiatives to enhance research training such as writing groups for publication or grant application (McVeigh et al., 2002; Cumbie et al., 2005), group supervision (McCarthy et al., 2010), and multi-faceted institutional strategies (Gething and Leelarthaepin, 2000; Cooke et al., 2002; Green et al., 2006). A comprehensive review (Segrott et al., 2006) notes the lack of evidence to support such RCB strategies. One grounded theory study (Worrall-Carter and Snell, 2003) used a purposive sample of 20 nurse academics from 7 Australian universities to explore their perceptions of research and scholarship. Two case studies (Green et al., 2006, 2007) combine data on staff experience of RCB strategies with research outputs. Green et al. (2006) showed progress in a single academic department of RCB strategies over a five-year period yielding 27 of 112 (24\%) staff with or studying at doctoral level and a number of promotions to higher academic grades. This site was then compared with a second (Green et al., 2007) whose outputs were 14 of 48 (29\%) staff with/studying at doctoral level and a smaller number of promotions. Boyd et al. (2009) in a UK survey of 'new' ( $<6$ years) lecturers in nursing, midwifery or allied health professionals, showed $12 \%$ of 155 respondents holding a doctorate.

Many outlines of institutional support do not give specific practical details to assist those grappling with the RCB issue and evaluations/ outcomes of these strategies are limited. Hence, the quality and quantity of research outputs are rarely evaluated in sufficient depth, despite the fact that research outcomes ultimately determine the excellence of an institution (Thompson and Darbyshire, 2013). This paper maps an exemplar of successful RCB in one School of Nursing and Midwifery in Ireland, Trinity College Dublin, through its research outputs over a tenyear timeframe. A previous concept analysis (Condell and Begley, 2007) showed that one key element for RCB is financial investment. This paper shows how creative management of funding was utilised in order to achieve strategic research goals, 'shedding light on the situated process' (Segrott et al., 2006; p649), absent from much of the previous literature.

\section{Charting the Baseline}

The School of Nursing and Midwifery opened in Trinity College Dublin (TCD) in September 1996, with two members of academic staff. One lecturer was employed to develop the curriculum for, and run, the new Diploma in Nursing with an initial intake of 78 general nursing students, followed by intakes in successive years of psychiatric nursing and intellectual disability nursing students also. The other academic (Director of the School) was charged with the task of developing such post-registration and post-graduate courses as were deemed necessary. Over the next 6 years, 20 courses were developed and staff numbers increased to 14 , all funded from course fees.

In 2002, all nurse tutors $(\mathrm{n}=21$ ) qualified to Master's degree level, who worked in six hospitals linked with the university ( 2 general, 2 mental health and 2 intellectual disability services) assimilated into TCD. From 2002 to 2004, a further 12 nurse tutors assimilated into the School as they achieved Master's degrees. In the period 2002-2010 11 academic staff were appointed by open competition, and 5 staff left. In 2006 a further 13 children's nursing and midwifery tutors assimilated from linked hospitals (Fig. 1).

All nurse and midwife tutors assimilating held Diploma, Bachelor's or Master's degrees in education of 2-3 years' length and had recent, often extensive, experience of curriculum development. New challenges were that nurse and midwife tutors had to adapt to a less teaching-focussed and more research-driven working life. In traditional schools of nursing/midwifery, they would not have been expected to conduct research. Other challenges included, for the period 2002 to 2004, double-teaching the Diploma in Nursing and the new BSc in Nursing at the same time, sometimes in the original schools of nursing due to lack of accommodation in the university. In addition, tutors with experience of teaching small to moderate-size groups of $20-80$, had to adapt their teaching methods to suit group sizes of 40-200. They were also expected to take on complex course administration roles for which they had no experience. Old challenges co-existing at this time were that, prior to the assimilation in 2002, staff in the School of Nursing and Midwifery, TCD, had been out-numbered by the number of courses run, leading to excessive teaching and administration workloads (Fig. 2).

In 2002, only 11 staff in the School (31\%) held $(n=5)$, or were undertaking $(n=6)$, a doctorate. Swift action needed to be taken to kick-start the School's research agenda and to prepare staff members for a research career. The strategic plan for 2000-2005 had, necessarily, set goals in relation to the development of the structures and governance of the rapidly expanding School, encompassing the national assimilation of nurse tutors, and these goals had been achieved. A concomitant expansion of undergraduate and postgraduate student numbers took place (Figs. 3 and 4) and new accommodation was sourced and renovated, paid for by the Department of Health. A Director of Staff Education and Development was appointed to work with all new academics. Introductory courses were provided on the academic's role, time management and introduction to research opportunities. The preparation phase had thus been completed and solid structures had been set in place upon which new developments could be built.

\section{Method}

The strategic plan for 2005-2010 set ambitious plans to develop the research capacity of all staff, with the ultimate aim of changing the culture and ethos in the School to one of research-led academic excellence. Three research outcome goals were set:

\section{$>$ Goal 1: To ensure that, by $2010,75 \%$ of staff will hold, or be undertak- ing, a $\mathrm{PhD}$ \\ $>$ Goal 2: To increase the level of funded research by $20 \%$ per year \\ $>$ Goal 3: To increase peer-reviewed publications and professional conference presentations by staff, by $20 \%$ per year.}

The action plan (below) set out a series of dynamic interventions planned at different levels, with differing foci, which were designed to develop the ability of all staff to achieve the objectives (Condell and Begley, 2007). Initially, monies intended for a Chair position (€200,000 per annum, including salary, expenses and support staff) were devoted to kick-start the research strategic plan and, in subsequent years, salary savings from the RCB scheme were reserved and used for this purpose also.

A plan that would provide opportunities for different staff members with differing and diverse needs (see 'academic leave', 'student stipends' and 'reduced teaching load'), would reduce barriers to participation (see 'research maintenance funding' and 'inviting junior staff members onto research teams'), enable collaboration and networking (see 'Visiting Professors' and 'inviting junior staff members onto research teams') and provide facilities for mentoring (see 'Visiting Professors', 'senior appointments', 'inviting junior staff members onto research teams' and 'improving the research culture') (Farmer and Weston, 2002) was devised.

\section{Academic Leave}

Three month academic (sabbatical) leave can, in theory, be given to academic staff in TCD every 3 years but in practice, this is rarely awarded as it is perceived that other staff will have to take on more teaching. As the School's systems and structures were developed where none previously existed, a plan was put in place to ensure that 
$1996 \mathrm{~N}=2$

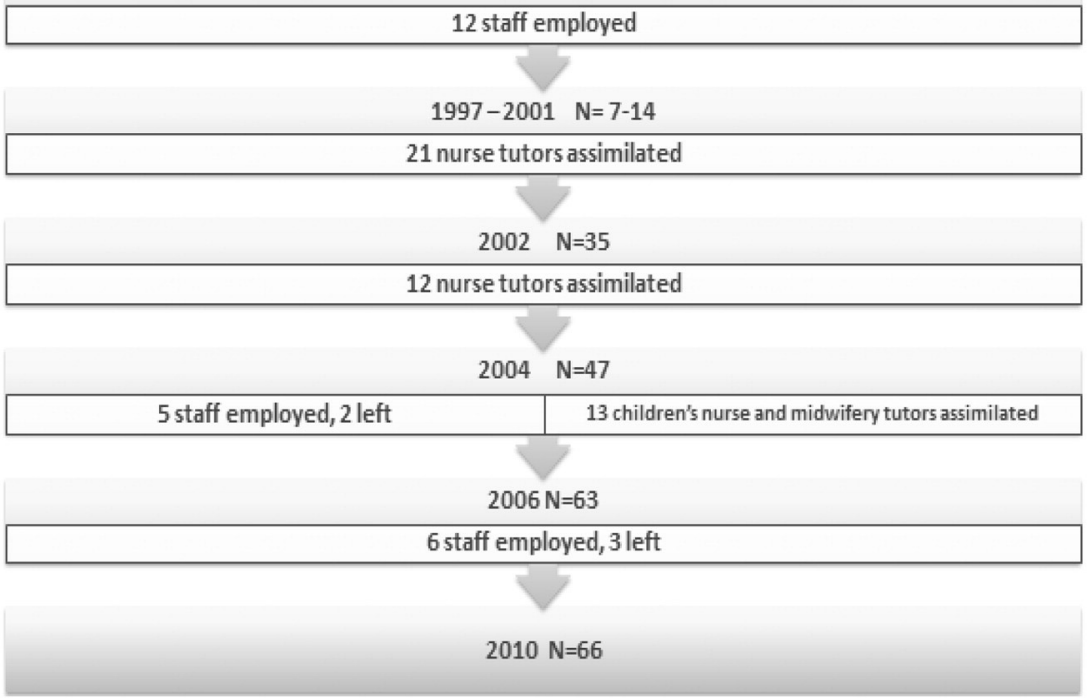

Fig. 1. Increase in School staff numbers due to two national assimilation processes and open competition.

5-6 staff could take 3 month leave in each of the 3 teaching terms. With 50 staff, the teaching allocation was thus divided by 45.5 , not 50 , to arrive at an annual norm per staff member (Box 1). Staff received leave in rotation to commence, expedite, or complete doctoral studies. Leave was cost-neutral, as it had been built into the teaching allocation plans.

\section{Student Stipends}

The fees of all staff undertaking PhDs in TCD were covered by the School, and staff choosing to undertake a $\mathrm{PhD}$ in another university could apply for some assistance with fees. In addition, any staff member registered for a PhD in TCD, could take 1-3 years of unpaid leave from their post. They could then apply for a student stipend, which allowed the School to employ them as a PhD student on a tax-free stipend of $€ 46,000$ (approximately equal to their after-tax take-home salary). There were no pension or sick-leave benefits as this was a tax-free position, and for each person awarded a stipend, Human Resources in TCD received a letter from the Revenue Commissioners agreeing the student's position. Stipends were competitive, and only awarded to people who had a detailed, high-quality research proposal. In the first year, 3 were awarded and this continued annually up to a maximum of 11 awards made in 2008 (Figs. 5-7).

This scheme was funded in the first year by $€ 200,000$ saved by delaying employment of a Chair in Nursing, supplemented by a competitive strategic development award from TCD of $€ 65,000$ (Fig. 5). Subsequently, this annual amount was supplemented by salary savings from the previous year, from the academics' salaries who had taken unpaid

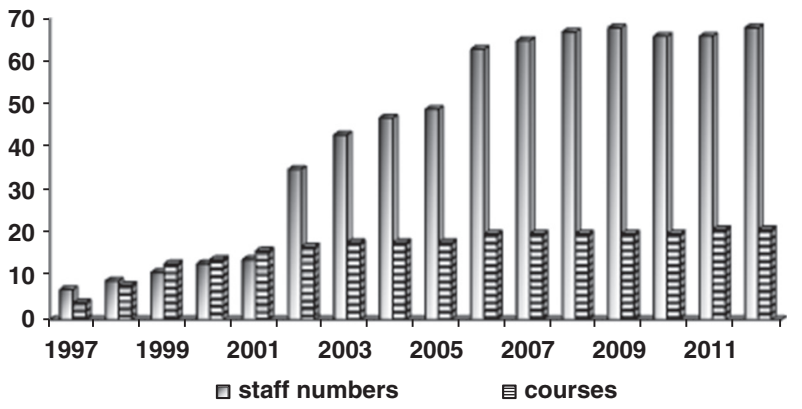

Fig. 2. Academic staff numbers and courses (1997-2012). leave, or were awarded Health Research Board Fellowships to undertake doctoral studies. Part of each salary was used to employ clinical tutors - one for every two staff released - or, occasionally, a temporary lecturer on a starting-grade salary. The clinical tutors were experienced nurses or midwives, educated to Master's level and had undertaken a one-year teaching diploma enabling them to register with An Bord Altranais as Nurse Tutors. All staff on stipends continued to teach $20 \mathrm{~h}$ per year, to keep their teaching skills current and to ensure that input for key curriculum areas was still available. Students' education was thus equivalent to the education they would have received from the newly assimilated nurse academics who had taken study leave.

Clinical tutors were required to teach twice the number of contact hours that academics taught, as they had no research remit, and their salaries were approximately half an academic's as they were employed in term-time only. Thus, for every two academics released, only one clinical tutor was employed, at the cost of half a salary. In addition to classroom teaching, clinical tutors gave extremely valuable clinical teaching in practice settings, and were very positively evaluated by students. Eventually, 9 clinical tutors were employed to cover all leaves, and the posts have been retained even when academics returned to their positions, in lieu of employing academics as posts came up.

All members of staff awarded a student stipend were expected to apply for external, competitive, research funding by the end of their

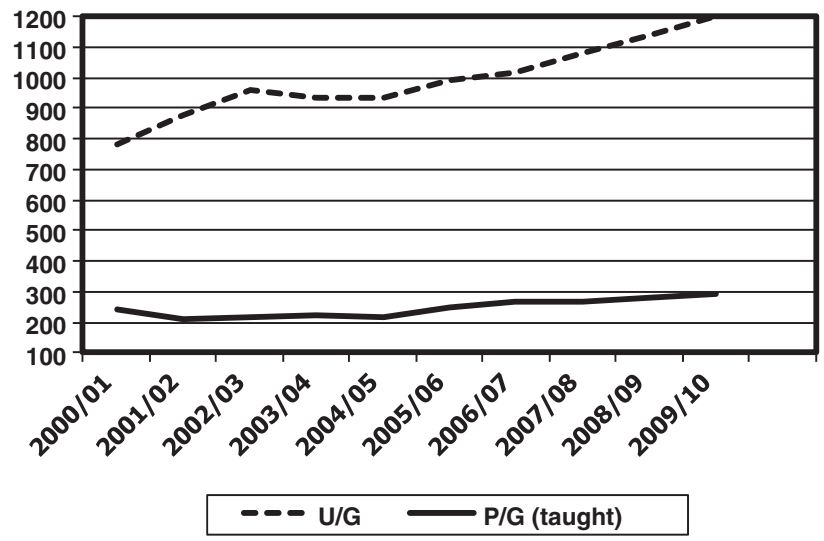

Fig. 3. Undergraduate and postgraduate student numbers (taught courses; 2000-2010). 


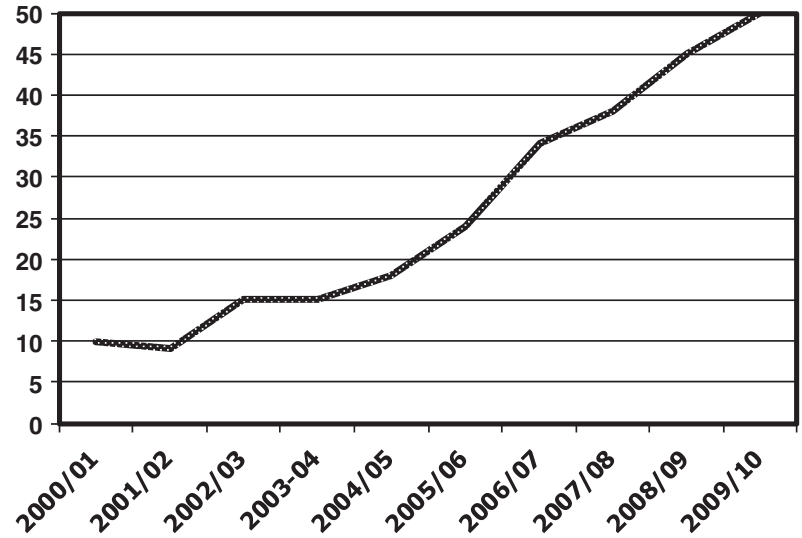

Fig. 4. Postgraduate research student numbers (2000-2010).

first year. As they were employed as full-time research students, and could devote all their time to these applications, the success rate of submissions was high, which meant that their subsequent 2-3 years of PhD support was free to the School. This released extra monies into the RCB sch. to pay for more student stipends, and increased the School's research funding totals.

\section{Reduced Teaching Load}

Some staff members were unable to take the stipend, due to concerns about pension requirements, sick-leave or maternity leave needs, so another scheme was instituted. Reduced teaching loads (30-40 h fewer per annum) were awarded to staff members who were not eligible at that time for an official sabbatical, but who were undertaking a $\mathrm{PhD}$. This was competitive and only awarded when applicants had a good proposal, were registered for a $\mathrm{PhD}$ and supported by their supervisor. Ideally, applicants were advised to relinquish $30 \mathrm{~h}$ of teaching in the same term so that they had an uninterrupted period of time for data collection, analysis, or writing-up. A number of staff were able to win a reduced teaching load in their third year, in conjunction with an official period of university academic leave, thus having six months off, plus the summer months, to write up their thesis. The teaching load was covered by the clinical tutors, or temporary lecturers, employed from unused salary amounts the previous year, so other staff members did not have an increased workload.

In addition to the 4.5 clinical tutors employed for the initial stages of the RCB scheme (Figs. 5-7), a further 4.5 were employed by the School, instead of 2.5 lecturer posts as vacancies arose. This extra teaching capacity covered maternity or long-term sick leaves, and relieved senior

\section{Box 1}

Example of allocation of teaching to allow every staff member to have 3 months of sabbatical every three years.

Scenario 1 Total of 6680 direct contact hours to be taught by 50 full-time equivalent (FTE) staff $=134 \mathrm{~h}$ per staff member (no sabbaticals)

Scenario 2 Total of 6680 direct contact hours to be taught by 32 FTE staff and 15-18 0.75 FTE staff (i.e., teaching $110 \mathrm{~h})=147 \mathrm{~h}$ per FTE staff member.

15-18 staff are given a 3 month sabbatical every year (5-6 per term, depending on other leaves such as maternity and long-term sick leave), with a reduced teaching load of $110 \mathrm{~h}$, provided they have a concrete and ambitious research plan.

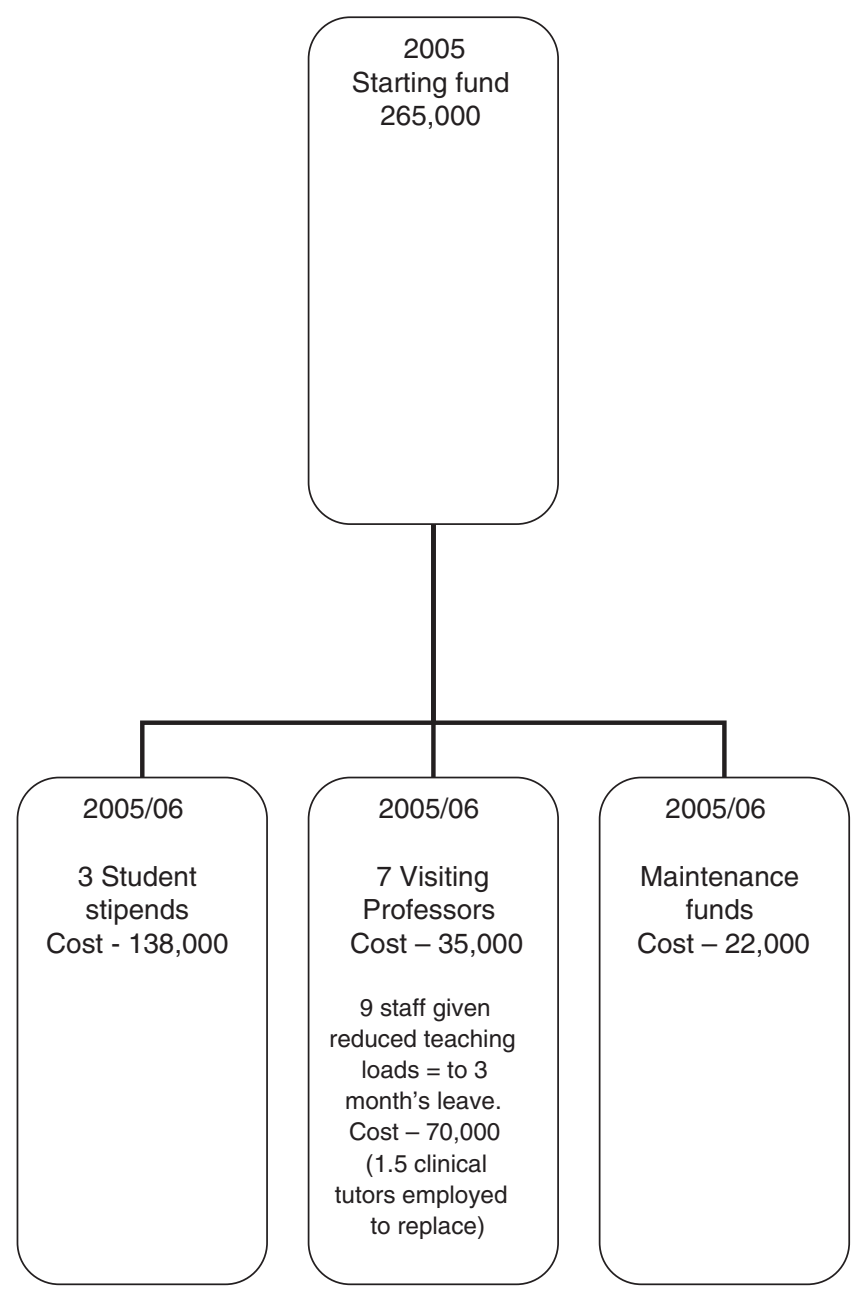

Fig. 5. Disbursement of strategic funds in 2005/06.

staff in administrative positions (e.g., Directors of Teaching and Learning, Director of Research) of some of their teaching load to assist them in developing their research careers. With this spare capacity, up to 16 RCB 'reduced teaching loads' could be awarded per year, depending on how many maternity/sick-leaves occurred in that period.

\section{Visiting Professors}

As only 5 staff members in the School held PhDs, it was difficult initially to cope with supervision requirements of all staff members undertaking PhDs. To supplement the supervisory capability, 7 Visiting Professors (VPs) were engaged, from the United Kingdom or United States, following international advertisement. The VPs agreed to: visit the School for a week, three times each year; co-supervise some PhD students; advise and assist junior academics with their research development; give master-classes at the monthly PhD seminar day; and act as external advisors on student 'transfer to PhD' assessments. Some VPs also took part in funding applications, and co-authored papers. VPs received all travel and living expenses and a small honorarium.

\section{Research Maintenance Funding}

Part of the RCB monies were disbursed to staff as research maintenance funding, up to a limit of $€ 1000$ per annum each, with the aim of increasing staff publications and presentations, and funded research. All academic staff receive up to $€ 700$ per annum from TCD to fund research conference travel. Newly appointed staff could also apply for competitive Research Start-up Grants of up to $€ 10,000$, and were expected to apply for external funding within two years. To supplement 


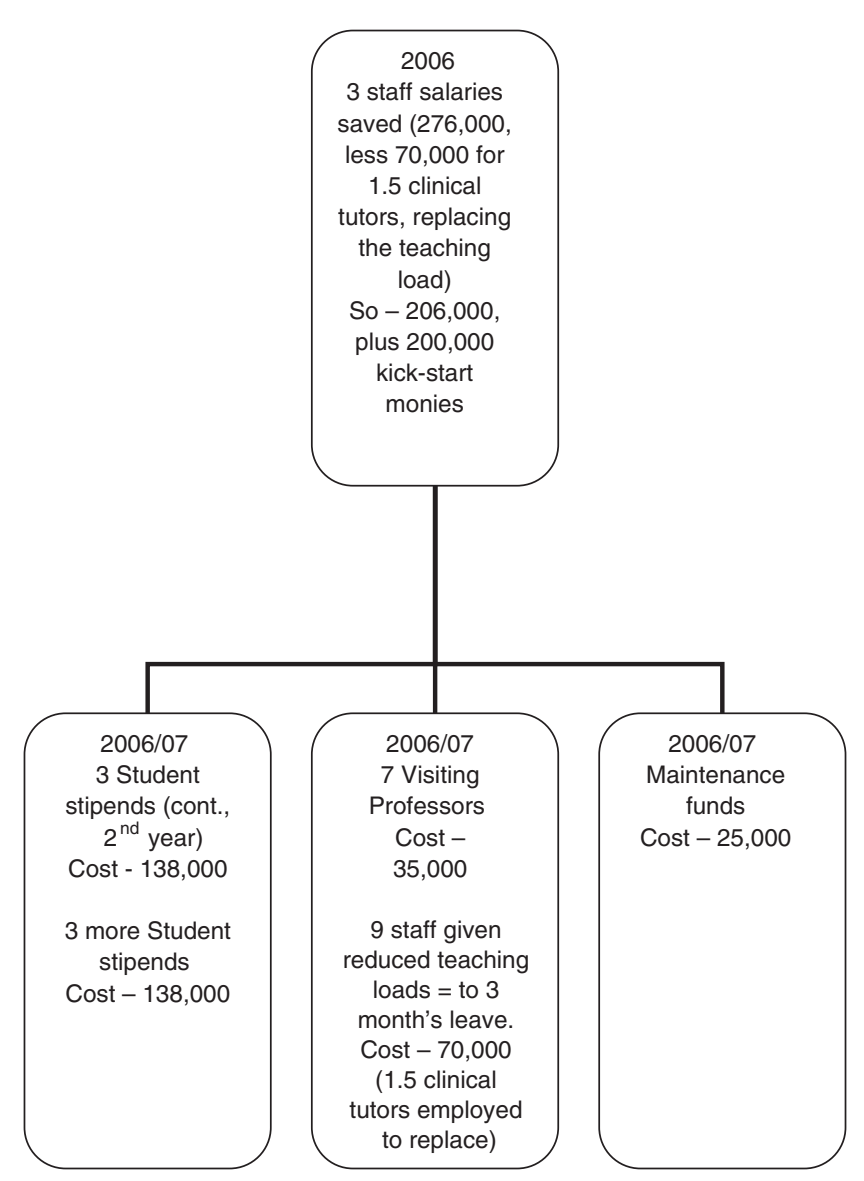

Fig. 6. Disbursement of strategic funds in 2006/07.

this, the School awarded up to $€ 1000$ to each staff member, based on their previous year's research output. The amounts given depended on seniority, with early lecturers receiving $€ 200$ if they were undertaking a $\mathrm{PhD}$, or any research study, €200 if they achieved previous year's objectives from their 5 year plan, $€ 200$ for peer-reviewed publications and $€ 100$ for conference presentations. Professors would receive $€ 100$ for peer-reviewed publications, €25 for conference presentations, $€ 200$ if principal investigator on a research proposal for funding, and $€ 200$ if working on a funded research project. Monies awarded were used to supplement the College conference travel grant, pay for openaccess publications, buy books, lap-tops or audio recording equipment, pay appropriate course fees, transcribers of recorded interviews, data inputters, or statisticians.

\section{Senior Appointments}

A strategic decision was taken to advertise all permanent appointments in 2005-2010 at Senior Lecturer/Associate Professor level. This resulted in a number of senior appointments, although most of them were awarded, following competitive interview, to existing staff members who applied. Our ratio of senior $(n=10)$ to junior $(n=58)$ posts is, however, still much lower than in other disciplines.

\section{Inviting Junior Staff Members Onto Research Teams}

For the initial few years, senior academics in the School opened their research teams to all volunteers who wished to join in a funding bid and undertake set projects to gain research experience. This provided supportive mentoring and enabled some collaborative work. Participants in these schemes all went on to undertake doctoral studies and many are now leading on their own research bids and repeating the cycle of inviting junior colleagues to join as co-applicants.

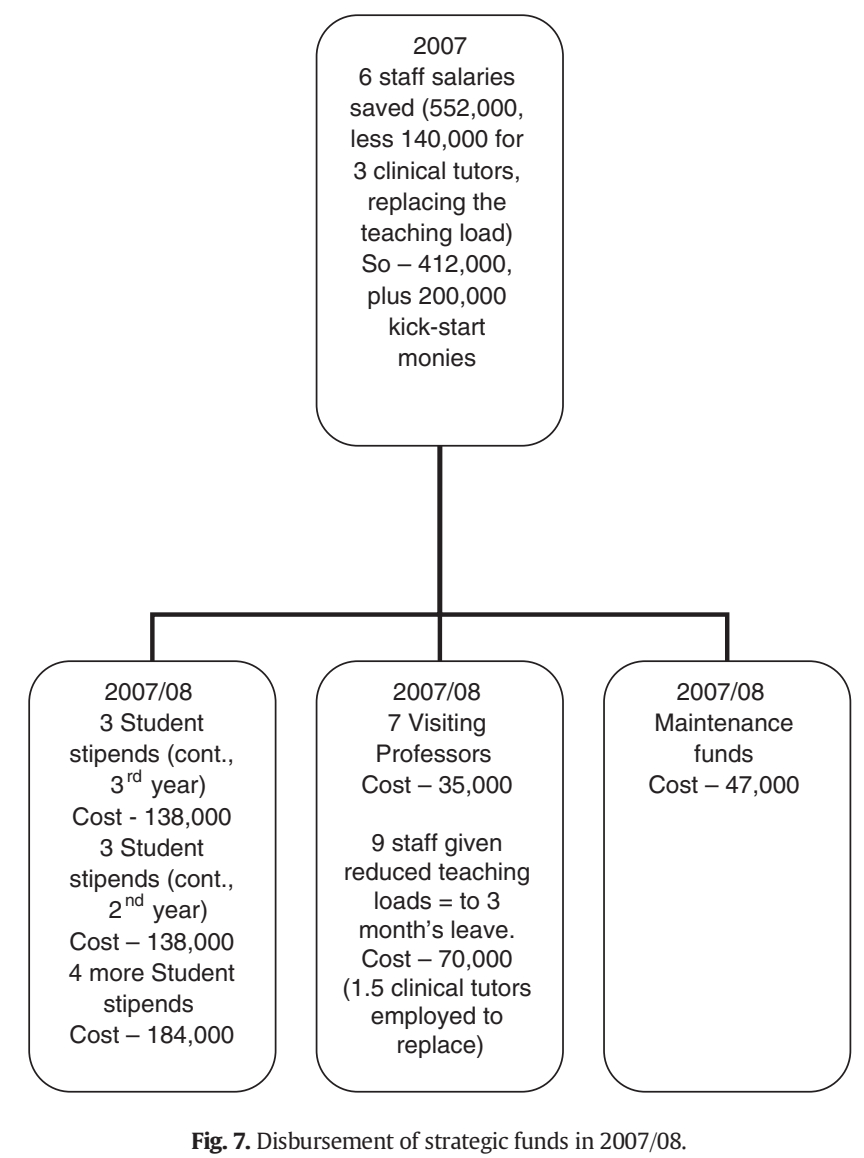

Improving the Research Culture

To support staff and students undertaking PhDs, and increase exposure to research, monthly $\mathrm{PhD}$ seminar days were instituted. Students present their research to this group in their second year as part of their 'confirmation/transfer to PhD' assessment; Visiting Professors give masterclasses, and advice sessions are held. A programme example is in Fig. 8.

\section{Results}

Goal 1 had been that, by $2010,75 \%$ of staff would hold, or be undertaking, a PhD. In 2010, out of 66 academic staff, 52 either held $(n=23)$ or were undertaking $(\mathrm{n}=29)$ a $\mathrm{PhD}(79 \%)$, thus surpassing the goal (Fig. 9). In 2012, 38 staff now hold a PhD (55\%) and a further 17 (25\%) are undertaking one ( 55 out of $69,80 \%$ ), so this trend is continuing.

Goal 2 was to increase the level of funded research by $20 \%$ per year from 2005 to 2010. In 2004, $€ 570,000$ of research funding was received. Over the 5 -year period a $20 \%$ increase each year should have amounted to a total of $€ 5,090,054$. The actual achieved was $€ 6,351,101$, equivalent to $28 \%$ increase each year, thus surpassing goal 2 .

The third goal was to increase peer-reviewed publications and conference presentations by staff, by $20 \%$ per year. In 2004, there were 41 staff publications and 57 conference presentations. Over the period 2005-2010, the total number of publications, increasing by $20 \%$ each year, should have reached 366, with 508 presentations. The actual numbers achieved were 439 publications (27\% increase) and 512 presentations (20\% increase each year). Goal 3 was thus also surpassed (Fig. 10).

\section{Discussion}

The authors of the editorial published in NET in 2001, prior to the move of nurse and midwife tutors into third-level education in Ireland 
C. Begley et al. / Nurse Education Today xxx (2013) $x x x-x x x$

\begin{tabular}{|c|c|c|}
\hline 15-Jan-13 & $0900-1000$ & $\begin{array}{c}\text { Methodological Master Class } \\
\text { 'Quality in qualitative research matters' } \\
\text { Dr. XY }\end{array}$ \\
\hline 15-Jan-13 & $1000-1030$ & Break \\
\hline 15-Jan-13 & $1030-1130$ & $\begin{array}{l}\text { Transfer/Confirmation Presentation } \\
\text { Modelling the Health Outcomes of Opiate Users and their Children } \\
\qquad X Y\left(2^{\text {nd }} \text { year student }\right)\end{array}$ \\
\hline 15-Jan-13 & $1130-1300$ & $\begin{array}{l}\text { Methodological Master Class } \\
\text { 'Introduction to Qualitative data Analysis - toddler phase' } \\
\text { Prof. XY }\end{array}$ \\
\hline 15-Jan-13 & $1300-1400$ & $\begin{array}{c}\text { Professor Seminar lecture Series } \\
\text { Developing a service user engagement strategy in healthcare } \\
\text { education } \\
\text { Prof XY, Director, Centre of Practice } \\
\text { and Healthcare Innovation, Trinity College Dublin }\end{array}$ \\
\hline 15-Jan-13 & $1400-1500$ & PhD Support (Students meeting among themselves) \\
\hline 15-Jan-13 & $1500-1600$ & Supervisors Meeting (Supervisors meeting among themselves) \\
\hline 15-Jan-13 & $1600-1700$ & $\begin{array}{l}\text { Research Advice and Data Analysis Clinic } \\
\text { (qualitative) }\end{array}$ \\
\hline 15-Jan-13 & $1630-1730$ & $\begin{array}{l}\text { Research Advice and Data Analysis Clinic } \\
\qquad \text { (statistics) }\end{array}$ \\
\hline
\end{tabular}

Fig. 8. Example of a $\mathrm{PhD}$ research support day.

(McKenna and Coates, 2001), did not appear to believe that these educators could survive the transition, reminding readers of "the thousands of extinct species who have disappeared because they were not able to adapt to changing climates and situations." (p. 423). Referring to the nurse and midwife educators, they questioned whether we should "accept Darwinian-like that only the academic fittest will survive?" (McKenna and Coates, 2001, p. 423). The published rebuttal spoke of the support, encouragement and facilitation that Irish nurse tutors would receive and of how their skills and contribution would be valued as they moved into their "new and exciting careers" (Begley, 2001, p. 596).

The results of the exemplar presented here have shown how, in the specific setting of one Irish University School of Nursing and Midwifery, these tutors were supported to further their academic careers by undertaking the "hurdle" of a PhD (Jackson et al., 2011). Those strongly motivated responded well to the facilitation methods provided, as has been found in other studies promoting allied health professionals to advance their research knowledge (Pager et al., 2012). The enthusiastic response

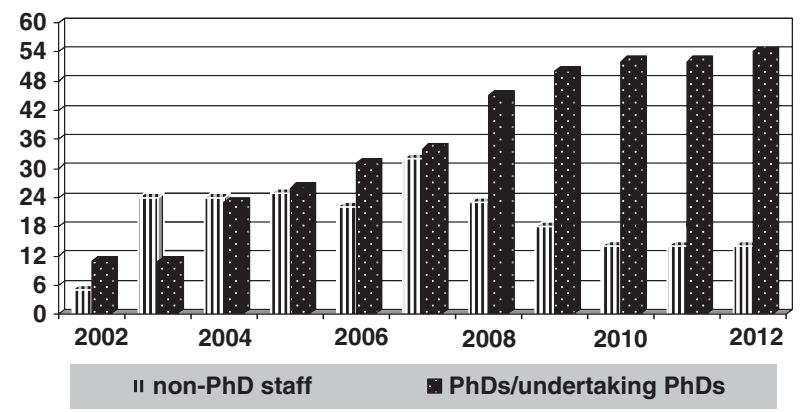

Fig. 9. Staff numbers without PhDs, and those with or undertaking PhDs (2002-2012). from staff will result in at least $80 \%$ of the School's staff being educated to $\mathrm{PhD}$ level, a sound basis for any academic department in a researchled university. The School's activities would also rank highly on a recently-developed tool for testing $\mathrm{RCB}$ at institutional and individual levels (Holden et al., 2012), fulfilling all recommended sections. Whilst not a focus of this paper, there has also been a shift from individual research to research as a team-based activity, supported by competitive programmatic funding. In part, this is due to those who completed their PhDs early, particularly in clinical topics, continuing on to develop higher-order research skills, including supervision of doctoral students and leadership of interdisciplinary and international research teams.

The challenge of workload management to free up research time is well known (Green et al., 2006, 2007). This exemplar describes how some of the challenges inherent at organisational level have been overcome by active strategic management. The significant changes seen in this exemplar were achieved by the strategic delay, for just three years, in the appointment of a Chair in Nursing.

An additional resource has been utilised with the formation of the clinical tutor role for term-time teaching. Their employment has the

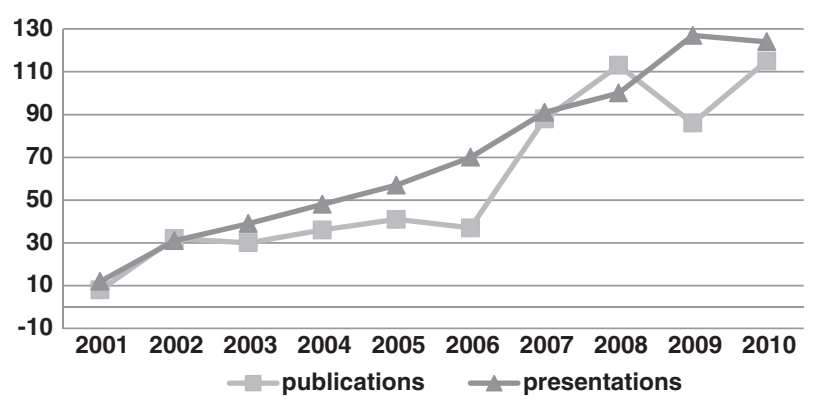

Fig. 10. Peer-reviewed publications and conference presentations by staff. 
strategic aim of releasing academics to undertake PhDs and other research, rather than merely being a reactionary 'stop-gap' filling of vacant teaching posts (Halcomb et al., 2010; Jackson et al., 2011). In comparison to elsewhere, the ratio of these 'sessional staff' to tenured staff is 1:4.5 as opposed to 1:2 (Andrews et al., 2010; Jackson et al., 2011), they are prepared to Master's level, teach in class as well as in clinical areas and are supported in their teaching skill development and professional recognition. Two have continued studies at doctoral level, with the aim of applying for academic posts in the future.

Higher education literature has noted the concept of 'critical mass' for optimal research culture and RCB (Delamont, 1997; Hazelkorn, 2004); however, few have attempted to quantify this. It was noticeable in TCD that, as the percentage of staff undertaking/holding a PhD progressed past 50\%, discussions during $\mathrm{PhD}$ seminar days, and other fora, became more academic in nature. Whilst not all School staff undertook PhDs within the School, some choosing to register elsewhere in TCD, or other universities, they nevertheless availed of, and contributed to, PhD support days. Wood (2005) cites a number of $3 \mathrm{PhDs}$ per annum as providing a good research training environment for academic departments. The School, over the past ten years has hosted 30-60 PhD students per year, with an annual intake of 3-6.

As RCB is a developmental process, we suggest that a ten-year timeframe is more practicable than the five years used elsewhere (Green et al., 2007), when measuring PhD numbers, funding and dissemination outputs especially in local contexts where such challenges as relocation, and major curricular and course development are occurring simultaneously. Continued research capacity development in nursing and midwifery is essential, with the focus now on capacity building in the areas of post-doctoral, independent researcher, interdisciplinary research and research team leading.

\section{Conclusion}

Strong leadership and generous support and encouragement can change a primarily teaching-focussed culture to one of research-led academic excellence, within a strategic commitment to change. Such an increase in research focus may lead to more research-based teaching by nursing and midwifery academics. Nursing and midwifery students will be educated through a more research-focussed lens, with greater potential for an interest in research careers in the future. These are the building blocks that will assure nursing and midwifery's final and complete acceptance into the third-level education sector, and guarantee their continued development.

\section{Acknowledgements}

We pay tribute to the dedication and enthusiasm of all our colleagues in the School of Nursing and Midwifery, Trinity College Dublin, who together have made this tremendous achievement possible. We thank the Visiting Professors to the School for their assistance, and Human Resources in Trinity College Dublin for their help with the national assimilation of nurse and midwife tutors.

\section{References}

Andrew, S., Halcomb, E.J., Jackson, D., Peters, K., Salamonson, Y., 2010. Sessional teachers in a BN program: bridging the divide or widening the gap? Nurse Educ. Today 20, 453-457.

Begley, C.M., 2001. Nurse education in Ireland: redressing the balance. Nurse Educ. Today 21, 595-596.

Boyd, P., Smith, C., Lee, S., MacDonald, I., 2009. Becoming a Health Profession Educator in a University: The Experiences of Recently-appointed Lecturer in Nursing, Midwifery and the Allied Health Professions. The Higher Education Academy, York (Retrieved 14th February, 2013, from www.health.heacademy.ac.uk/lenses/publications/m10094. html).

Condell, S., Begley, C.M., 2007. Capacity building - a concept analysis of the term applied to research. Int. J. Nurs. Pract. 13, 268-275.

Cooke, J., Owen, J., Wilson, A., 2002. Research and development at the health and social care interface in primary care: a scoping exercise in one NHS region. J. Health Soc. Care Community 10 (6), 435-444.

Cumbie, S., Weinert, C., Luparell, S., Conley, V., Smith, J., 2005. Developing a scholarship community. J. Nurs. Scholarsh. 37 (3), 289-293.

Delamont, S., 1997. Critical mass and doctoral research: reflections on the Harris Report. Stud. High. Educ. 22 (3), 319-331.

Farmer, E., Weston, K., 2002. A conceptual model for capacity building in Australian primary health care research. Aust. Fam. Physician 31, 1139-1142.

Gething, L., Leelarthaepin, B., 2000. Strategies for promoting research participation among nurses employed as academics in the university sector. Nurse Educ. Today 20 (2), 147-154.

Government of Ireland, 1998. Report of the Commission on Nursing. The Stationery Office, Dublin.

Green, B., Segrott, J., Hewitt, J., 2006. Developing nursing and midwifery research capacity in a university department: case study. J. Adv. Nurs. 56 (3), 302-313.

Green, B., Segrott, J., Priest, H., Rout, A., Mclvor, M., Douglas, J., Flood, Y., Morris, S., Rushton, C., 2007. Research capacity for everyone? A case study of two academic nursing schools' capacity building strategies. J. Res. Nurs. 12 (3), 247-265.

Halcomb, E.J., Andrew, S., Peters, K., Jackson, D., Salamonson, Y., 2010. Casualisation of the teaching workforce: implications for nursing education. Nurse Educ. Today 30, 528-532.

Hazelkorn, E., 2004. Growing research: challengers for late developers and newcomers. High. Educ. Manag. Policy 16 (1), 119-140.

Holden, L., Pager, S., Golenko, X., Ware, R.S., 2012. Validation of the research capacity and culture (RCC) tool: measuring RCC at individual, team and organisation levels. Aust. J. Prim. Health 18, 62-67.

Jackson, D., Peters, K., Andrew, S., Salamonson, Y., 2011. “If you haven't got a PhD, you're not going to get a job": the PhD as a hurdle to continuing academic employment in nursing. Nurse Educ. Today 31, 340-344.

Lazzarini, P., Geraghty, J., Kinnear, E.M., Butterworth, M., Ward, D., 2013. Research capacity and culture in podiatry: early observations within Queensland Health. J. Foot Ankle Res. 6 (1). http://dx.doi.org/10.1186/1757-1146-6-1.

McCarthy, G., Hegarty, J., Savage, E., Fitzpatrick, J.J., 2010. PhD away days: a component of PhD supervision. Int. Nurs. Rev. 57 (4), 415-418.

McKenna, H., Coates, V., 2001. The future of nurse education in Ireland. Nurse Educ. Today 21, 421-422.

McVeigh, C., Moyle, K., Forrester, K., Chaboyer, W., Patterson, E., John, W.S., 2002. Publication syndicates in support of nursing scholarship. J. Contin. Educ. Nurs. 33, 63-66.

Murray, J., Campbell, A., Hextall, I., Hulme, M., Jones, M., Mahony, P., Menter, I., Procter, R., Wall, K., 2009. Research and teacher education in the UK: building capacity. Teach. Teach. Educ. 25, 944-950.

Pager, S., Holden, L., Golenko, X., 2012. Motivators, enablers, and barriers to building allied health research capacity. J. Multicult. Health 5, 53-59.

Segrott, J., McIvor, M., Green, B., 2006. Challenges and strategies in developing nursing research capacity: a review of the literature. Int. J. Nurs. Stud. 43, 637-651.

Thompson, D., Darbyshire, P., 2013. Editorial: is academic nursing being sabotaged by its own killer elite? J. Adv. Nurs. 69 (1), 1-3.

White, E., 2003. Occupational therapy research: building capacity. Br. J. Occup. Ther. 66 (5), 224-226.

Wood, M., 2005. Comparison of doctoral programmes. Clin. Nurs. Res. 14 (1), 3-10.

World Health Organisation, 2009. Global standards for the initial education of professional nurses and midwives. Retrieved 20th April, 2013, from http://www.who.int/hrh/ nursing_midwifery/hrh_global_standards_education.pdf.

Worrall-Carter, L., Snell, R., 2003. Nurse academics meeting the challenges of scholarship and research. Contemp. Nurs. 16, 40-45. 